\title{
STUDY OF PATTERN OF PSYCHOACTIVE SUBSTANCE USE IN PATIENTS ADMITTED TO A REHABILITATION CENTRE
}

\author{
Harisha Delanthabettu1, Kasturi Pandiyan², Vidya Shankar M. H³, Fredrick Braggs ${ }^{4}$, Shubha N. Vijayakumar ${ }^{5}$
}

1 Professor, Department of Psychiatry, KVG Medical College and Hospital, Sullia, D. K., Karnataka.

${ }^{2}$ Associate Professor, Department of Psychiatry, MVJ Medical College and Research Hospital, Hoskote, Bangalore, Karnataka.

${ }^{3}$ Assistant Professor, Department of Computer Science, Sahyadri Science College, Shimoga, Karnataka.

4 Director, Ashakirana De-Addiction and Rehabilitation Centre, Bhadravathi, Karnataka.

5Vimalasri Consultation, Siddaruda Nagara, Bhadravathi, Karnataka.

\section{BACKGROUND}

ABSTRACT

Substance abuse is a common phenomenon in the world and has invaded the human society as the most important social damage.[1,2] Substance abuse is a non-adaptive model of drug use, which results in adverse problems and consequences and includes a set of cognitive, behavioural and psychological symptoms.[3]

The aim of this study is to help in community intervention and rehabilitation.

The objective of this study is to know the recent trends in psychoactive substance use in the community from the inmates admitted to a rehabilitation centre.

\section{MATERIALS AND METHODS}

This is a cross-sectional study conducted from 1st March 2016 to 28th February 2017 at 'Ashakirana,' a rural de-addiction and rehabilitation centre at Bhadravathi, Shimoga District [Recognised by Ministry of Social Justice and Empowerment, Govt. of India]. A total of 292 patients with substance dependence were included in the study using a semi-structured interview schedule. SCAN and ICD-10 sampling were done according to convenience. Statistical analysis was performed using SPSS V 19 software. Descriptive analysis was used. Ethical clearance was obtained.

\section{RESULTS}

Males constitute only $98 \%$ of the study population. The mean age of initiation of substance use is 23.9 years. The study shows that $242(82.9 \%)$ are from rural background. Among the polysubstance dependence, the most frequent substance combination encountered is that of alcohol and tobacco $48 \%$ [18 out of 34 patients].

\section{CONCLUSION}

Substance dependence is a multidimensional problem. It involves not only the individual, but also the community in diverse ways.

\section{KEYWORDS}

Psychoactive Substance Use, De-Addiction and Rehabilitation Centre, Community.

HOW TO CITE THIS ARTICLE: Delanthabettu H, Pandiyan K, Shankar VMH, et al. Study of pattern of psychoactive substance use in patients admitted to a rehabilitation centre. J. Evolution Med. Dent. Sci. 2018;7(13):1607-1610, DOI: 10.14260/jemds/2018/364

\section{BACKGROUND}

Substance dependence has been showing a raising trend all over the world including India. India has a population of over 1 billion people and it is estimated that there are about 62.5 million alcohol users and about 3 million victims of different kinds of substance abusers, excluding alcohol dependents.

Alcohol and other substance related behavioural and medical complications are of a major concern for policy planners and health professionals of most of the countries.

According to a UN report one million heroin addicts are registered in India, and unofficially there are as many as five million.(4)

'Financial or Other Competing Interest': None.

Submission 23-08-2017, Peer Review 09-03-2018,

Acceptance 17-03-2018, Published 26-03-2018.

Corresponding Author:

Dr. Kasturi Pandiyan,

Associate Professor,

Department of Psychiatry,

MVJ Medical College and

Research Hospital, Hoskote,

Bangalore, India.

E-mail:drkasthurip@gmail.com

DOI: $10.14260 /$ jemds $/ 2018 / 364$

(c) $($ ) $९$
What started off as a casual use among a minuscule population of high-income group youths in the metro has permeated to all sections of society. Inhalation of heroin alone has given way to intravenous drug use, that too in combination with other sedatives and painkillers. This has increased the intensity of the effect, hastened the process of addiction and complicated the process of recovery. Cannabis, heroin and Indian-produced pharmaceutical drugs are the most frequently abused drugs in India. Cannabis products often called charas, bhang or ganja are abused throughout the country, because it has attained some amount of religious sanctity because of its association with some Hindu deities.[3] The International Narcotics Control Board in its 2002 report released in Vienna pointed out that in India persons addicted to opiates are shifting their drug of choice from opium to heroin.

In last three decades, many epidemiological surveys have been carried out in India to assess the prevalence of substance abuse. In Uttar Pradesh, Dube and Handa[5] reported that 22.8 per 1000 were dependent on alcohol and drugs, while Thacore ${ }^{6]}$ from Lucknow gave a figure of 18.55 per 1000. The important finding of these studies is that alcohol was the commonest substance used $(60 \%$ - 98\%) followed by cannabis use (4\% - 20\%). Epidemiological 
surveys ${ }^{[7,8]}$ also revealed that $20 \%-40 \%$ of subjects above 15 years are current users of alcohol and $10 \%$ of them are regular or excessive users.

In a rural population of Uttar Pradesh, alcohol was found to be the commonest substance abused (82.5\%) followed by cannabis (16.1\%). Varma et al[9] found that rates of current use of alcohol in Punjab were $45.9 \%$ in Jalandhar and $27.7 \%$ in Chandigarh, whereas it was $28.1 \%$ in rural areas of Punjab.[10] Shukla[11] reported that $38.3 \%$ of the rural population in Uttar Pradesh was habitual substance users. In a study conducted in rural community in Bihar, prevalence of alcohol/ drug use was found to be $28.8 \%$ of the study population.[12]

Comprehensive strategy involving specific programmes to bring about an overall reduction in use of drugs has been evolved by the various government agencies and NGOs and is further supplemented by measures like education, counselling, treatment and rehabilitation programmes. ${ }^{4}$ Substance abuse can be addressed at the individual level, at the local level (Soviet National, etc.) and at the cross-national level. At the individual level, there has to be a synthesis of biological understanding with the exploration of background, sociocultural factors. At the national and cross-national level, there has to be a concerted effort of all the countries in managing the issue of substance abuse, taking into account the local socio-cultural and political. In this effort, our centre the one at Bhadravathi is making specific programmes to bring about an overall reduction in use of drugs [Recognised by Ministry of Social Justice and Empowerment, Govt. of India].

\section{Aim}

To help in community intervention and rehabilitation.

\section{Objective}

To know the recent trends in psychoactive substance use in the community from the inmates admitted to a rehabilitation centre.

\section{MATERIALS AND METHODS}

This is a descriptive study conducted at 'Ashakirana,' a rural de-addiction and rehabilitation centre at Bhadravathi, Shimoga District [Recognised by Ministry of Social Justice and Empowerment, Govt. of India].

The patients admitted between 1st March 2016 and 28th February 2017 were considered for the study. A total of 292 patients with substance dependence were included in the study.

A semi-structured interview schedule was used to collect information on socio-demographic data.

SCAN,(13) Schedules for Clinical Assessment in Neuropsychiatry version 2.0 WHO (93 - 94) was administered. SCAN,(13) Schedules for Clinical Assessment in Neuropsychiatry version 2.0 WHO (93 - 94) was administered. SCAN is a set of instruments aimed at measuring and classifying the psychopathology and behaviour associated with the major psychiatric syndromes of adult life. It has 4 components. The tenth edition of present state examination (PSE-10), the glossary of differential definition, the item group check list (IGC) and the clinical history schedule (CHS).
Present state examination has two parts- Part one covers the somatoform disorders, dissociative anxiety, depressive and bipolar disorders, and problems associated with the basic bodily function and use of alcohol and other substances.

There is a screen for part two conditions. Part two covers psychotic and cognitive disorders and observed abnormalities of speech, affect and behaviour. Data from the schedules can be recorded in a variety of ways in SCAN schedules themselves. In coding booklets or by computer programme.

Patients with minimum diagnosis of dependence syndrome [ICD-10](14) were included in the study. Sampling was done according to convenience. Statistical analysis was performed using SPSS V 19 software. Descriptive analysis was used.

\section{RESULTS}

A total of 292 patients with substance dependence were included in the study.

\begin{tabular}{|c|c|c|}
\hline Sex & Number & Percentage \\
\hline Male & 287 & 98.29 \\
\hline Female & 5 & 1.71 \\
\hline \multicolumn{3}{|c|}{ Table 1. Sex Distribution } \\
\hline
\end{tabular}

Females Constitute only 2\% of the Study Population

\begin{tabular}{|c|c|c|}
\hline Age & Number & Percentage \\
\hline $10-19$ & 1 & 0.34 \\
\hline $20-29$ & 48 & 16.4 \\
\hline $30-39$ & 119 & 40.7 \\
\hline $40-49$ & 80 & 27.5 \\
\hline $50-59$ & 39 & 13.3 \\
\hline Above 60 & 5 & 1.7 \\
\hline Total & $\mathbf{2 9 2}$ & $\mathbf{1 0 0}$ \\
\hline \multicolumn{3}{|c|}{ Table 2. Age Distribution } \\
\hline
\end{tabular}

- The Majority are in the productive age group.

- No significant numbers are seen in the early age groups (10 - 19 yrs.) and above 60 years.

- The mean age of initiation of substance use is 23.9 years.

\begin{tabular}{|c|c|c|}
\hline Social Status & \multicolumn{2}{|c|}{ Percentage } \\
\hline Below poverty line & \multicolumn{2}{|c|}{70.2} \\
\hline Above poverty line & \multicolumn{2}{|c|}{29.8} \\
\hline Rural & 242 & 82.9 \\
\hline Urban & 50 & 17.1 \\
\hline Table 3. & $\overline{E c o n o}$ & \\
\hline
\end{tabular}

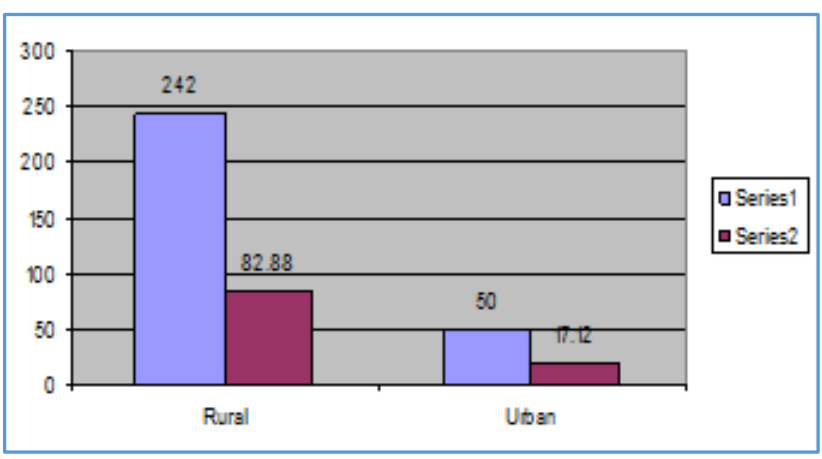




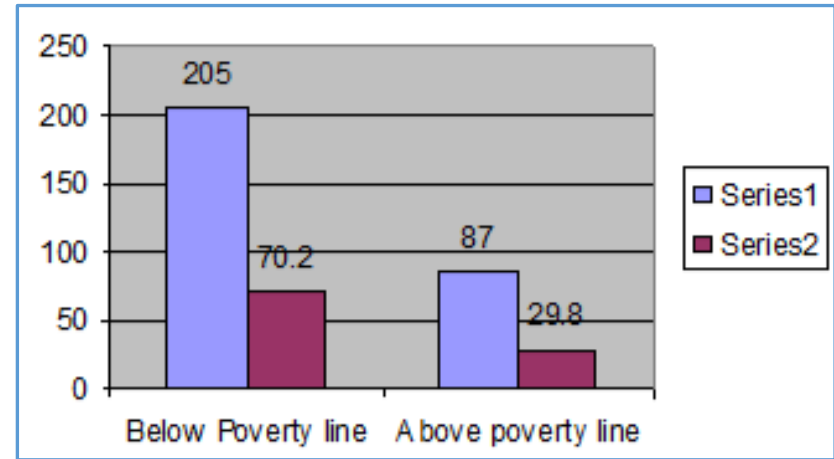

Most of them belong to Low Socio-Economic Status. The Study shows that 242 (82.9\%) are from Rural Background

\begin{tabular}{|c|c|c|}
\hline Substances Used & Number & Percentage \\
\hline Alcoholic dependence & 253 & 87 \\
\hline Dependence on cannabinoids & 3 & 1 \\
\hline $\begin{array}{l}\text { Dependence on volatile } \\
\text { solvents }\end{array}$ & 2 & 1 \\
\hline Polysubstance users & 34 & 11 \\
\hline Total & 292 & 100 \\
\hline
\end{tabular}

\begin{tabular}{|c|c|c|}
\hline & Number & $\%$ \\
\hline Alcohol with tobacco & 16 & 48 \\
\hline Alcohol with cannabinoids & 8 & 24 \\
\hline Alcohol with opioids & 5 & 15 \\
\hline Alcohol with volatile solvents & 3 & 08 \\
\hline Alcohol with sedatives & 2 & 05 \\
\hline Total & 34 & 100 \\
\hline
\end{tabular}

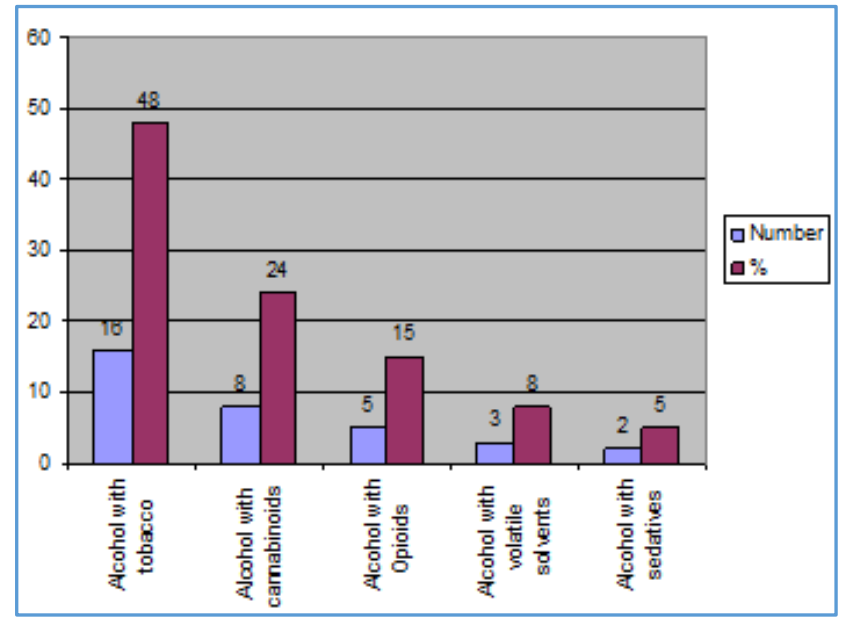

- Among the polysubstance dependents, the most frequent substance combination encountered is that of alcohol and tobacco $48 \%$ [ 18 out of 34 patients].

- It is observed that amongst the alcohol dependence (253 cases) $87 \%$ patients have associated smoking, though it does not fulfil the criteria for multiple drugs.

\section{DISCUSSION}

In the present study, $98 \%$ of substance dependents are males and females are predominantly abstinent. This goes well with other studies from.(4) The results show that $87 \%$ of the patients are dependent on alcohol and $11 \%$ of the study group are polysubstance dependents. However, some of the recent studies show an increasing trend in polysubstance dependence. Dependence on volatile solvents is significant. One of the case reports (IJP April - June 2008)(15) show a steady increase in inhalant dependence between 2002 and 2005. The inhalant abuse either in school dropouts or pupils irregular to school is alarming.

The productive age group is involved, as the majority of the dependents are between 20 - 49 years of age. The mean age of the patients with substance dependence seeking treatment is $34.6 \mathrm{yrs}$. In the present study, $70 \%$ of the patients are from low socio-economic group and $82.9 \%$ are from rural background. The previous studies showed that the individuals with income below poverty line and people from rural areas had higher relative odds of tobacco and alcohol use compared to their counterparts.

The mean age of initiation of substance use remains the same. Early age of initiation is observed in subjects with dependence on volatile solvents. Among the polysubstance dependents, alcohol is the common substance of abuse. The most frequent substance combination encountered was that of alcohol and tobacco (53\%) followed by alcohol and cannabinoids (24\%). The majority of the studies bring out similar results reflecting the real picture of substance use pattern in the community.

It is interesting to find that among alcohol dependent cases (253) 87\% have associated tobacco use, mostly smoking, though it does not fulfil the criteria for multiple substance dependence. According to the National household survey, alcohol use was found in $21 \%$ of the adults. Alcohol use among women was consistently less than $5 \%$. The survey found that the prevalence of regular use of tobacco, either through smoking or in chewable form is around $30 \%$.

\section{CONCLUSION}

Substance dependence is a multidimensional problem. It involves not only the individual, but also the community in diverse ways. Hence, community intervention is highly relevant in the management of substance use.

\section{Implication}

Currently, the Government of India in association with the Ministry of Social Justice and Empowerment has funded 483 de-addiction-cum-Rehabilitation Centres and 90 Counselling and Awareness Centre's countrywide and it has been implementing the Scheme for Prohibition and Drug Abuse Prevention since the year 1985 - 86.

- The focal point of the program is drug demand reduction by reducing overall consumption.

- High risk group approach and community programs. Education and information dissemination to create a high degree of public awareness.

- $\quad$ Public health paradigm and incorporating it in primary health care.

- Strengthening social welfare system/ criminal justice system.

- To carry out prevention and intervention activities with the participation of various government, nongovernmental and community based organisations. The basic objective of creating facilities for treatment at Centres run through voluntary organisations is to ensure 
that the support of the family and the community is mobilised to the maximum.

- The rehabilitation and social reintegration of the dependent and comprehensive program for after-care and follow-up.

\section{REFERENCES}

[1] Poor RA. A guide for prevention and treatment of substance abuse. Tehran: Salman Publication 2004: p. 13, 23-4, 32, 17, 53, 143, 51-4.

[2] Siam SH. Drug abuse prevalence in male students of different universities in Rashtin 2005. Tabibe Shargh Publisher 2006;8:279-84.

[3] Madadi A, Nogani F. The text book of addiction and substance abuse. Tehran: Jameanegar 2004: p. 10.

[4] Nadeem A, Rubeena B, Agarwal VK, et al. Substance abuse in India. Pravara Med Rev 2009:1(4):4-6.

[5] Dube KC, Handa SK. Drug use in health and mental illness in an Indian population. $\mathrm{Br} \mathrm{J}$ Psychiatry 1971;118(544):345-6.

[6] Thacore VR. Drug abuse in India with special reference to Lucknow. Indian J Psychiatry 1972;14(3):257-61.

[7] Dube KC, Kumar A, Kumar N, et al. Prevalence and pattern of drug use amongst college students. Acta Psychiat Scand 1978;57(4):336-56.
[8] Lal B, Singh G. Drug abuse in Punjab. Br J Addict 1979;74(4):411-19.

[9] Varma VK, Singh A, Singh S, et al. Extent and pattern of alcohol use and alcohol-related problems in North India. Indian J Psychiatry 1980;22(4):331-7.

[10] Lal B, Singh G. Alcohol consumption in Punjab. Indian J Psychiatry 1978;20(3):212-16.

[11] Shukla BR. Drinks and drugs in a north Indian villagean anthropological study. Ethnographicand Folk Culture Society: Lucknow, India, 1979.

[12] Jena R, Shukla T, Pal H. Drug use in a rural community in Bihar: some psychosocial correlates. Indian J Psychiatry 1996;38(1):43-6.

[13] SCAN. Schedules for Clinical Assessment in Neuropsychiatry version 2.0. WHO (93-94).

[14] World Health Organization. The ICD-10 classification of mental and behavioural disorders: clinical descriptions and diagnostic guidelines. Geneva: World Health Organization, 1992.

[15] Benegal V, Velayudhan A, Jain S. Social costs of alcoholism: a Karnataka perspective. NIMHANS Journal 2000;18(1 \& 2)67:1-12. 